\title{
Los discursos alrededor de la partitura: lecturas acerca de la identidad en la obra de Pedro Ximénez desde la perspectiva del narrativismo de Frank Ankersmit
}

\author{
Discourses around the score: \\ Readings on identity in the work of \\ Pedro Ximénez from the perspective of \\ Frank Ankersmit's narrativism \\ por \\ Zoila Vega Salvatierra \\ Departamento de Artes de la Universidad Nacional \\ de San Agustín de Arequipa, Perú \\ zvega@unsa.edu.pe
}

Frank Ankersmit ha propuesto que los discursos y representaciones históricas, lejos de interferir unos con otros, pueden complementarse y ayudar a construir visiones más completas del fenómeno que se está estudiando. El presente artículo intenta aplicar esta perspectiva a diferentes representaciones construidas en torno a la obra del compositor Pedro Ximénez Abrill, referidas a la identidad. La narración histórica que elijamos construir a partir de la interpretación de los datos en la fuente musical escrita podría ser una de las muchas posibles construcciones discursivas que son igualmente válidas y que, sin que suponga inexactitud y poca fiabilidad, contribuirían a cimentar una mejor visión del pasado desde su multiplicidad.

Palabras clave: Narrativismo Histórico, identidad, música latinoamericana del siglo XIX, Pedro Ximénez Abrill.

Frank Ankersmit has proposed that historical discourses and representations, far from interfering with one another, may complement each other and help to construct more complete visions of the phenomenon studied. The present article tries to apply this perspective to different representations built around the work of the composer Pedro Ximénez Abrill, referred to identity. The historical narrative that we choose to construct from the interpretation of the data in the written musical source could be one of the many possible discursive constructions that are equally valid and that, without implying inaccuracy and unreliability, would contribute to build a better vision of the past from its multiplicity.

Keywords: Historical narrativism, identity, 19 th century Latin American music, Pedro Ximénez Abrill. 


\section{INTRODUCCIÓN}

Junto con Arthur Danto y Hayden White, Frank Ankersmit (Holanda, 1945) es uno de los representantes de la filosofía narrativista de la historia, si bien con una perspectiva algo distinta de los dos primeros. Para Ankersmit, el historiador crea significado histórico en su escritura acerca del pasado -un fenómeno que él llamó "representación", como se explicará más adelante-, donde decide y construye una narración que se convertirá en la representación del hecho histórico, pero que no es el hecho histórico en sí. Esto supone una posibilidad infinita de construcción de "representaciones" por parte de historiadores que eligen opciones diferentes y que, por tanto, elaboran nuevas narraciones, a menudo contradictorias, en torno a un mismo fenómeno o hecho histórico. En este estudio se pretende explicar, desde esta perspectiva narrativista, la cuestión de la identidad en un compositor sudamericano del primer tercio del siglo XIX.

\section{LA PROPUESTA DE ANKERSMIT}

En su libro Historia y Tropología, Frank Ankersmit delimita varias propuestas en torno al discurso histórico. Según Ankersmit, el hecho de que el pasado no pueda ser objeto de la experiencia porque no puede ser recreado es un problema serio en la investigación histórica. En las ciencias naturales, el objeto de estudio, la naturaleza, presenta cierta estabilidad, cierta continuidad, que permite la aplicación de las mismas leyes. En cambio, la realidad del pasado, que es el objeto de investigación histórica, no posee esa estabilidad, no puede recrearse en el presente y no presenta la misma continuidad y estabilidad de un fenómeno natural. Para superar este problema, el investigador recurre a experiencias dejadas por el pasado, pero que no son el pasado en sí, y construye, a base de dichas experiencias, discursos históricos que no son el pasado mismo, sino lo que Ankersmit ha llamado "representaciones, máscaras que el historiador asigna para un pasado que no tiene rostro" (Ankersmit 2014: 198). Por tanto, cada investigador elabora sus propias representaciones (el filósofo se resiste a llamarlos relatos o narrativas para evitar confusiones con los géneros literarios) y la diversidad de dichas representaciones no pretende generar consensos, sino que estimula la aparición de tesis interpretativas.

El propósito de la historiografía no es la transformación de las cosas narrativas en cosas reales. Al contrario, intenta producir la disolución de lo que parece conocido e indubitable. Su objetivo no es la reducción de lo desconocido a lo conocido, sino el extrañamiento de lo que parece conocido (Ankersmit 2014: 87).

Además, establece que la diversidad de interpretaciones o representaciones históricas no son necesariamente excluyentes ni divergentes entre sí y pueden ayudar a elaborar un panorama más rico acerca del fenómeno estudiado desde distintas perspectivas, aunque posean las mismas fuentes en las que apoyan sus conclusiones y discursos (Ankersmit 2014: 223).

1 El presente trabajo surge a partir de la investigación doctoral titulada La composición académica como fuente testimonial del género popular: el yaravi temprano en la obra de Pedro Ximénez de Abril y Tirado que la autora realizó como alumna del programa de doctorado en musicología de la Facultad de Música de la Universidad Nacional Autónoma de México (UNAM). 


\section{DEFINIENDO LA PARTITURA}

Aunque en los últimos años la musicología ha expandido sus objetos de investigación más allá de la partitura, esta continúa siendo, en muchos campos de estudio, una fuente valiosa que permite reconstruir un pasado elusivo, especialmente a falta de otras fuentes contextuales, ayudándonos a elaborar discursos en torno a un tiempo anterior al nuestro. De acuerdo con lo enunciado en la sección anterior, podríamos considerar la partitura escrita como una experiencia del pasado, no el pasado en sí mismo, y que puede emplearse para construir una representación de él. Incluso podríamos afirmar que la partitura es un "artefacto" en el sentido arqueológico del término, que además de medido, pesado y estudiado en la zona del hallazgo y en el laboratorio, debe ser interpretado contextualmente $^{2}$. La partitura, además de sus elementos intrínsecos, puede ser relacionada con su entorno, pudiendo elaborarse a base de ella discursos históricos diferentes, quizás incluso divergentes, pero que pueden ser complementarios entre sí.

Si estamos dispuestos a aceptar la partitura como fuente histórica que se expresa mediante la escritura, sería útil recordar que Peter Burke ha señalado que los registros escritos, "no son concreciones inocentes de recuerdos sino más bien intentos de persuadir, de moldear la memoria de los demás" (Burke 2000: 70). Esto es particularmente cierto con la escritura musical, empleada como recurso nemotécnico para la transmisión de información sonora en el transcurso del tiempo. Además, la intención del investigador de servirse de la partitura como fuente histórica, y no como representación gráfica de un producto sonoro creado con fines estéticos (o religiosos o sociales, dependiendo de la función asignada) encuentra desde el comienzo esta doble dificultad de, por un lado, ser un producto originalmente pensado para otro fin que el que queremos asignarle (resulta difícil probar la "intencionalidad" del compositor de crear una fuente histórica al momento de escribir la partitura) y, por otro, no ser un reflejo fiel de algo que sucedió en el pasado (la partitura no recrea el pasado). Además la partitura, al igual que un texto histórico, puede ser una metáfora, como la define Ankersmit (2014: 144-145), ya que no significa literalmente lo que dice (ni en el plano histórico ni en el sonoro), y mientras más interpretaciones existan y puedan establecerse relaciones entre ellas, mejores posibilidades habrá para desentrañar su significado como fuente escrita para la historiografía.

Ahora bien, si se trata de una partitura que registra elementos propios de la cultura popular, se acrecienta la zona gris de la investigación histórica. Carlo Ginzburg ha sido enfático al calificar las fuentes escritas que tratan la cultura popular como productos de culturas de élite que hablan de culturas subordinadas y las interpretan a su manera (Ginzburg 1999: 3) y, por tanto, dichas fuentes tampoco son absolutamente precisas ni fiables. En estos casos, el compositor actúa como miembro vinculado a la cultura de élite que interpreta a su manera y con una motivación propia los contenidos de la cultura popular que emplea en su obra.

2 Usaremos aquí la descripción de "artefacto" enunciada por el arqueólogo Francisco Contreras Cortés: "Los artefactos nos proporcionan una de las dimensiones formales referentes a la excavación arqueológica, ya que pueden ser medidos tanto cuantitativamente (sus atributos mensurables) como de manera cualitativa (sus atributos o rasgos reconocibles). Los artefactos también tienen una dimensión espacial: su localización tridimensional en el registro arqueológico. Su distribución vertical o estratigráfica representa su cronología y su distribución horizontal muestra cómo se relacionan con otros artefactos, representando actividades y funciones" (Contreras Cortés 1984: 327-328). 


\section{EL CASO XIMÉNEZ}

Para estudiar cómo diferentes interpretaciones o teorizaciones pueden integrarse en una perspectiva más amplia, según lo propuesto por Ankersmit, analizaremos algunas proposiciones directas o indirectas en torno a la obra del compositor peruano-boliviano Pedro Ximénez Abrill (Arequipa, 1784?-Sucre, 1856), pues en su lenguaje técnico encontramos un tratamiento de la forma, melodía y ritmo propio del estilo galante europeo de la segunda mitad del siglo XVIII, un lenguaje armónico sólido y bien reglamentado por las teorías en boga de la misma época, y un tratamiento de los géneros camerísticos muy semejante al que también es posible encontrar en Europa a finales de esa centuria ${ }^{3}$.

Además de estas características, en obras de cámara como el Divertimento Concertante para guitarra, dos flautas y cuarteto de cuerdas, op. 43, el Cuarteto Concertante, op. 55, piezas vocales como la Oda a Safo para voz y guitarra, Yaraví $N^{o} 8$ para voz y piano, obras escénicas como la tonadilla El militar retirado en triunfo y la patriota pastorcita, o religiosas como Meditaciones para el quinario, escritas para cuarteto de cuerdas y dos flautas, y Las Cinco llagas, para dos tiples, dos flautas y cuarteto de cuerdas, Ximénez emplea en forma explícita material oral de géneros como el yaraví y danzas sesquiálteras conocidas en la época como danzas de la tierra, cielitos, o danzas de pañuelo, según los distintos lugares de procedencia, emparentadas con el fandango español o mestizadas con ritmos africanos. Asimismo, en otras obras suyas, especialmente las de guitarra, encontramos yaravíes, pasacalles y valses que tenían mucho éxito entre los asistentes a tertulias domésticas de salón a finales del siglo XVIII y comienzos del XIX. Los géneros orales y los de salón empleados por Ximénez eran de uso común en las ciudades en las que vivió (Arequipa y Sucre) en el lapso de su vida ${ }^{4}$. Nuestro ejercicio, entonces, intentará explicar el uso de ambos estilos o vertientes en la obra ximeniana desde perspectiva de la identidad, debido a que se trata de un compositor que vivió en un período crucial de la historia del continente, como es el final del régimen colonial y el inicio de la vida independiente, época en que los países sudamericanos empezaban a construir sus identidades nacionales como consecuencia del nuevo orden político.

En este caso en concreto, la obra de Pedro Ximénez no es una fuente inocente, para usar el término de Burke, y contiene a su vez un discurso ideológico propio que tal vez no sea explícito, debido a la ausencia de cartas o escritos personales del compositor que expliquen las elecciones estilísticas y temáticas que hizo en su vida, aunque sea posible especular

3 No es propósito de este artículo hacer un análisis exhaustivo de las obras y estilos abordados por Pedro Ximénez Abrill. Para conocer su más reciente biografía ver Izquierdo y Vega 2017; acerca del Cuarteto, op. 55 y el uso del yaraví en él, véase Izquierdo 2016b. Para estudios de sus sinfonías, ver Izquierdo 2016c y Vargas 2012. Con relación a la presencia de géneros orales en música escrita en el Divertimento Concertante, op. 43, puede consultarse Vega 2018. Acerca de sus tonadillas, ver Izquierdo 2016a, y para estudios de su estilo, opciones de composición y entorno, ver Izquierdo 2018.

4 Hablar de nacionalidad en el caso Ximénez es un tema complejo, ya que el compositor vivió en dos ciudades muy similares entre sí en gustos y costumbres y que además poseían una larga historia en común. Cuando Ximénez nació, Arequipa y la entonces ciudad de Charcas (hoy Sucre) pertenecían a dos virreinatos diferentes (el de Perú y el de La Plata) pero dependientes de un mismo imperio, el español. La región natal de Ximénez poseía estrechos lazos económicos, sociales y culturales con la entonces Audiencia de Charcas, que ni siquiera las guerras de independencia o la posterior creación de Bolivia como país independiente pudieron destruir. Al migrar a Sucre en 1833, lo hizo en una época que coincidió con el intento de integración de la Confederación Perú-Boliviana y el posterior conato de anexión de Bolivia por parte del Perú. Tales acontecimientos pudieron haber influido en su discurso compositivo, pero carecemos de información para dar una explicación más profunda. Ximénez vivió toda su vida a caballo entre dos naciones que tenían mucho en común pero que pelearon encarnizadamente por mantenerse separadas. 
acerca de ellas y construir hipótesis que las expliquen. Cada uno de los historiadores/ investigadores/intérpretes de estas fuentes elaborarán una representación propia basados en su formación, experiencia, línea de investigación, personalidad, metodología, etcétera.

\section{TRES EJEMPLOS DE INTERPRETACIÓN DE LA PARTITURA XIMENIANA DESDE LA NOCIÓN DE IDENTIDAD}

De las tres perspectivas propuestas a continuación, solo la segunda, perteneciente a José Manuel Izquierdo, constituye un estudio específico acerca de obra de Ximénez. La primera es una aplicación al caso Ximénez a partir de la propuesta de Ricardo Miranda, y la tercera una aplicación de las nociones de discurso y poder desde la perspectiva de Michel Foucault en torno al uso de material popular en la obra del mencionado compositor, empleadas como ejemplo de aplicación al modelo Ankersmit.

a. La identidad en la música decimonónica latinoamericana. Una explicación desde la perspectiva de Ricardo Miranda

En la primera parte del libro La música en Latinoamérica Ricardo Miranda explica que las naciones latinoamericanas, durante el período inmediatamente posterior a su independencia política, se emplearon en la tarea de consolidar su identidad musical según los parámetros de organización de Europa, tanto con la creación de instituciones (academias, conservatorios, sociedades filarmónicas) como con el ejercicio de la composición, la interpretación y la audición, como se realizaban en el viejo continente (Miranda 2011: 37). Miranda enfatiza, además, en que "los latinoamericanos del siglo XIX adoptaron fehacientemente la idea de construir una identidad propia donde lo sublime tuviera un lugar relevante" (Miranda 2011: 64). Era importante mostrarse como países cultos y modernos. En este contexto, la noción de modernidad se obtenía al alcanzar las metas artísticas e intelectuales que exhibían los países de Europa occidental, especialmente Francia, Italia, Alemania e Inglaterra, potencias económicas, políticas y culturales de ese entonces. Al parecerse a ellas, los países americanos ganaban legitimidad como naciones independientes, libres de la tutela española, y merecedoras de ser reconocidas como tales. Entonces, los músicos americanos tenían la doble posibilidad de asumir lenguajes totalmente europeos en su creación sonora, o bien distinguirse de Europa construyendo una identidad audible opuesta a ella.

El autor hace notar que en el devenir de la historia musical latinoamericana ha primado la consideración de esta última como única posibilidad de construcción de la identidad, es decir, que se da por hecho que solo lo que suene opuesto o distinto a la música europea puede considerarse latinoamericano (Miranda 2011: 46).

Pero no siempre fue así. La primera opción, que señala que es posible conseguir legitimidad mediante el empleo de lenguajes europeos, se encuentra muy bien respaldada por Thomas Turino, quien, a propósito de un análisis somero de los himnos nacionales latinoamericanos, hace hincapié en que los países recién conformados en el proceso independentista, siguiendo el ejemplo de La Marsellesa francesa, no sintieron la necesidad de marcar una distinción estilística empleando elementos autóctonos o propios, ya que la idea de nación como unidad cultural diferenciada no obraba todavía como base de la legitimidad política. Los himnos debían mostrar similitudes, y no diferencias, con los de otros Estados existentes para ser considerados símbolos de Estados igualmente legítimos (Turino 2003: 179).

La ópera entra en esta categoría. Miranda ha señalado que es el género donde las sociedades latinoamericanas intentaron demostrar ser dignas de pertenecer a la cultura 
occidental, tanto consumiéndola como produciéndola, ya que era considerada como un "verdadero termómetro de la civilidad alcanzada" (Miranda 2011: 72). La idea de cultivar la semejanza para alcanzar la ansiada paridad, y por tanto el reconocimiento como naciones independientes, cultas y dignas de pertenecer al escenario internacional, es lo que impulsó tanto a creadores, intérpretes y público en general a preferir productos sonoros semejantes a los europeos ${ }^{5}$.

La segunda posibilidad, la de construir una identidad desde el uso de la diferencia, encuentra abundantes ejemplos en todo el repertorio nacionalista de finales del siglo XIX y la primera mitad del siglo XX, que finalmente catapultó a algunos autores americanos, nacionalistas o no, a la fama internacional y a su aceptación como parte del canon universal de música académica, entre ellos, Carlos Chávez y Heitor Villa-Lobos ${ }^{6}$. Es necesario subrayar, sin embargo, que esta primacía de lo diferente supone desestimar las producciones y expresiones que son similares, lo que explicaría por qué la música escrita antes de la aparición de los movimientos nacionalistas no tuvo la misma valoración y terminó cayendo en el olvido. Miranda ha observado que muchos de los discursos historiográficos en Latinoamérica han tratado el primer período del siglo XIX (el que busca la semejanza con Europa) de una manera peyorativa, y que incluso se le ha visto como "una auténtica edad media, precedida por el auge de la Colonia y de la que nos 'libró' la gran generación nacionalista" (Miranda 2011: 27). El repertorio del temprano siglo XIX ha sido considerado prenacionalista o decadente con relación al pasado colonial americano e indigno, por tanto, de comparación con las posteriores glorias sonoras del nacionalismo precisamente por su imitación del lenguaje europeo, negándole por tanto la categoría de objeto de estudio al no poseer esas características que lo hacen "auténticamente latinoamericano". Pero este repertorio merece ser estudiado y juzgado por sí mismo y en su contexto, y no en comparación con productos anteriores o posteriores o con estructuras de pensamiento propias de épocas distintas. No se trata de determinar si es el objeto de estudio lo que vale o no, sino la mirada y la palabra que se escribe acerca de él lo que se debe cambiar.

Esta perspectiva ayudaría a entender, dentro de la producción de Ximénez, el uso de materiales propios del estilo clasicista europeo de la segunda mitad del siglo XVIII: el empleo de instrumentos de cuerdas y de formas musicales como sinfonías (aunque más próximas a la escuela parisina que a la vienesa), la escritura de obras de cámara, ritmos y motivos emparentados con el minué y el rondó clásicos, y un largo etcétera. En la teorización de Miranda, podríamos encuadrar a Ximénez como el compositor americano que

5 Esta visión de la igualdad de méritos entre la música europea y la americana puede leerse incluso en escritos de aparición tardía, como la Filosofía elemental de la Música, de José Bernardo Alzedo (1788-1878), publicado en Lima en 1869, pero con un trabajo previo de larga data. En el apéndice de su tratado, Alzedo se refiere a la obra de François-Joseph Fétis, la Biographie universelle des musiciens et bibliographie générale de la musique. Supplément et complément (1834-1835) y se lamenta de que el autor haya omitido a autores americanos, pues considera que "en tres centurias de civilización, no ha podido faltar siquiera uno que pudiese ocupar al menos el último lugar en la estensa (sic) serie”, y para probarlo, menciona que en Perú conoció a varios maestros de gran mérito, incluyendo al "arequipeño D. Pedro Jiménez Abril (conocido vulgarmente como Pedro Tirado)" (Alzedo 2019 [1868]: 237). La necesidad de reconocimiento del talento americano es evidente en músicos de la generación de Alzedo y Ximénez. El mismo Alzedo, al hacer la crítica de la obra teórica de Fetis, la que, según explica, le llegó después de concluida la edición del libro, se comporta como un profesional emitiendo juicio acerca de la obra de un colega, que es su par.

6 La oscilación entre semejanza y diferencia en el siglo XX conducirá a los famosos debates entre nacionalistas y cosmopolitas que se encuentran en casi todas las escuelas compositivas latinoamericanas. Algunas de ellas, como la brasileña, dedicaron a estos encuentros abundante literatura. 
intentó ser igual a sus pares europeos por medio de un estilo que, en cierto momento, fue considerado universal, al igual que las ideas ilustradas.

Pero el grave inconveniente es que deja una parte importante de la obra ximeniana sin cobertura. Ximénez escribió tanto desde la semejanza como desde la diferencia, ya que en sus obras encontramos el lenguaje formal, melódico e instrumental propio del clasicismo europeo, pero también aparecen menciones a géneros orales, de salón o de calle que estaban vigentes en su tiempo, casi cincuenta años antes de la aparición del nacionalismo latinoamericano. Por tanto, ni la semejanza ni la diferencia absolutas nos sirven para describir a cabalidad la obra ximeniana.

b. Las categorías de Ilustración y Contrailustración: Izquierdo y la explicación desde la localidad y el cosmopolitismo

En su ensayo Ilustración y contrailustración de un cuarteto arequipeño (o cómo escribir un yaravi en el estilo de Haydn), José Manuel Izquierdo enuncia otra teoría igualmente explicativa acerca del uso de material tradicional en una obra en concreto: el segundo movimiento del Cuarteto Concertante, op. 55, de Pedro Ximénez, "Adagio con sordina”.

Izquierdo no cree que la presencia de este material, en este caso un yaraví, sea una manifestación nacionalista. Coincide con Miranda en que la música debe ser entendida en su propio contexto y debe definirse cuáles son los códigos que permiten explicarla. Desde esa perspectiva señala que, en la época de Ximénez, los códigos de aceptación en música no se leían como coloniales, periféricos o nacionalistas, sino que lo europeo era percibido como universal, uno de los postulados de la Ilustración. Asimismo, el lenguaje clásico al que Ximénez se adscribe era visto como representante de la modernidad, y suponía un cambio radical respecto de lo que se había escuchado antes en las colonias americanas. Para apoyar su explicación, Izquierdo cita las definiciones de Isaiah Berlin y Thomas Schlereth al decir que

uno de los aspectos claves del discurso ilustrado es la noción de que el conocimiento humano se desarrolla en estadios distintos, pero corresponde a un mismo espacio cultural, por lo que se ve la cultura de algunas ciudades europeas como una "cima" a la que todos los seres humanos deben aspirar. Es central para el ciudadano ilustrado el tomar información de diversos lugares y entenderse a sí mismo como parte de una cúpula que comparte una misma cultura, más allá de las fronteras geográficas y temporales (Izquierdo 2016b: 25).

Esto convertiría la obra de Ximénez en un producto ilustrado, parte de esa tradición cosmopolita enaltecida por los ideales ilustrados. Como vemos, el autor ofrece una explicación holística para el uso de diversos lenguajes, tanto europeos como americanos en un mismo corpus.

$\mathrm{Al}$ conjunto de postulados que reconocemos como pertenecientes a la Ilustración, se contrapone otro que hoy llamamos Contrailustración. Izquierdo no lo define completamente, así que citaremos al mismo Berlin, quien usa este término para referirse al conjunto de pensadores, en su mayoría alemanes, aunque también los hubo italianos y franceses, que combatieron los ideales racionalistas, universalistas y progresistas de la Ilustración. Particularmente las ideas de Gianbattista Vico y Johann Gottfried Herder pueden resultar de utilidad para explicar la singularidad en la obra de Ximénez. Vico sostenía que cada cultura expresa su propia experiencia colectiva, mientras que Herder creía que, para entender una religión o una obra de arte o un carácter nacional, se debía entrar en las condiciones de su vida, o en este caso, de su contexto (Berlin 2006: 62-71). La Contrailustración, entonces, es el desafío a la universalidad de la cultura, al sentido único de la historia y a la idea de 
que todas las civilizaciones son, en realidad, etapas más o menos avanzadas de un único camino hacia el progreso.

Para Izquierdo, la inclusión de melodías de yaraví en un cuarteto de cuerdas (y, por extensión, de otros géneros orales en música escrita en otras obras ximenianas) podría leerse como una expresión de la Contrailustración. Su uso de material tradicional es una respuesta, que intenta ser distinta pero que se inscribe dentro de la totalidad. "La distinción cosmopolita recalca, a su vez, las posibles diferencias nacionales dentro de un total civilizado, que abraza y cubre aquella diversidad. Sin embargo, creo que la distinción que hace el compositor no es entre América y Europa -he aquí el quid del asunto- sino entre una cultura cosmopolita y Atlántica, ilustrada y moderna, y las posibilidades propias de una dualidad con lo local" (Izquierdo 2016b: 34). Para Izquierdo, la presencia de materiales tradicionales en música académica de origen europeo responde a un esquema de diálogo entre la Ilustración y la Contrailustración. Desde su localía, Ximénez intenta legitimar su propio discurso apelando a la diferencia y la singularidad, postulados contrarios a los principios universales de la Ilustración. Por tanto, el producto cultural que suscribe no intenta ser parte de lo universal fundiéndose con lo cosmopolita, sino diferenciándose de él mediante citas que no existen en el canon europeo.

Pero parece poco probable que Ximénez hubiese tomado en consideración los postulados de la Contrailustración en su escritura musical, especialmente si tenemos en cuenta que las ideas de los filósofos de esta corriente no tuvieron tanta difusión en América Latina hasta varios años después de la Independencia americana, cuando se gestaron los discursos nacionalistas que son producto del Romanticismo, en tanto reacción contra la Ilustración. Esto sucedió cuando Ximénez ya había utilizado recursos tradicionales en sus composiciones, de manera que su propósito difícilmente podría calificarse de "contrailustrado", al menos en sus obras anteriores a 1830, aunque contribuye a explicar sus procedimientos. No existen tampoco otras fuentes como diarios, cartas o escritos personales o de la época que ayuden a esclarecer los motivos ideológicos del compositor o de los círculos intelectuales que frecuentaba.

c. La relación del discurso y el poder: un ejercicio foucaultiano para explicar el uso de elementos populares en partituras académicas

Si los géneros orales o de salón son empleados por Ximénez en composiciones académicas que además emplean lenguajes y estructuras neoclásicas, podrían emplearse herramientas de análisis del discurso para darle sentido a su intención. Proponemos, de nuestra parte, el siguiente ejercicio discursivo para completar este artículo.

Foucault, en su tesis acerca del discurso, señala que este es una expresión del poder, un vehículo para conservarlo y también un medio para pelear por él y contra él. En toda sociedad, los discursos se controlan y se distribuyen de manera tal que procuran la perpetración del poder y evitan cualquier peligro que lo amenace, pero a la vez suponen el medio por el que se le combate e incluso se le desplaza hacia nuevos centros (Foucault 1992: 11-12). Si el poder emplea los discursos para afianzarse y continuar su hegemonía, las fuerzas que intentan adueñarse de dicho poder también emplearán estos mismos discursos para lograr sus objetivos.

Si vemos las convenciones formales de la música europea de finales del siglo XVIII como mecanismos de poder representados en las prácticas musicales que, a su vez, son representadas como partituras, entonces podríamos establecer como hipótesis que las obras en las que Ximénez consigna material tradicional operan como si se tratasen de un discurso político, en el que Ximénez expresa tanto valores considerados universales como 
elementos de identidad locales a los que les concede el mismo nivel de importancia, y a los que presenta en igualdad de condiciones.

En los años inmediatamente anteriores a su tiempo, las élites criollas ya habían iniciado esta tendencia al pretender equiparar géneros tradicionales peruanos a la categoría de los españoles, como lo demuestra el artículo de "Sicramio" publicado en el Mercurio peruano en 1791, en el que pone a la misma altura al yaraví peruano con el fandango español, "que, así como los yaravíes son singulares; del mismo modo que el fandango no tiene igual" (Sicramio 1791: 29). Si bien este dato podría ayudar a sostener la primera de las interpretaciones enunciadas aquí (la de la identidad americana en igualdad de condiciones con la europea), no deja de llamar la atención la incisiva aseveración de "Sicramio", que manifiesta sin ambages la validez de un género peruano frente a uno peninsular. Los géneros musicales funcionan aquí como una metáfora de los pueblos: si un género peruano es equivalente a uno español, entonces también los peruanos son iguales a los españoles. Puede encontrarse en forma muy velada un discurso de igualdad que será la espina dorsal de la causa independentista dos décadas más tarde.

Es muy posible que Pedro Ximénez simpatizara con estas ideas de equivalencia con la cultura europea y por tanto con el proyecto independiente que se gestó en su juventud y madurez, como parecen demostrarlo sus relaciones familiares y amicales en la Arequipa de la segunda década del siglo XIX. Al utilizar música de procedencia oral en sus composiciones buscaría enunciar un manifiesto político, engarzando en estructuras europeas elementos provenientes de una tradición antagonista americana como una forma de adueñarse de ese poder por el que se enfrentaban peninsulares y americanos. En la realidad, el enfrentamiento venía dándose desde hacía varios años, agravado por las políticas económicas de la España borbónica y podría ser perfectamente posible que los debates no fueran únicamente políticos o literarios, sino también sonoros. Ximénez emplearía la música de cámara primero, y de iglesia después como medios discursivos para consolidar ideologías americanistas ${ }^{7}$, que buscaban equipararse en validez, contenido y forma con la española imperante en la época.

Pero, nuevamente en este caso, faltan fuentes conexas que puedan complementar esta idea. Ayudaría mucho, por ejemplo, conocer la obra de compositores contemporáneos y habitantes de zonas vecinas que emplearan recursos semejantes en su escritura musical para saber si se trata de una tendencia razonablemente común en la época, o si es el caso de un autor único. La carencia de fuentes musicales en este período magnifica la interrogante.

\section{LA INTEGRACIÓN DE LAS NARRACIONES}

Después de recorrer estas tres interpretaciones, regresamos a uno de los postulados de Ankersmit: "La idea histórica no tiene un carácter cognitivo sino que es en esencia una propuesta de cómo debe verse el pasado. No es conocimiento, sino una organización del conocimiento" (Ankersmit 2014: 189). Las interpretaciones mencionadas no son definitivas, últimas ni mutuamente excluyentes. Suponen, como diría Hayden White, un "acto poético", una prefiguración del campo histórico para poder explicarlo desde su propia narrativa (White 1992: 39). O tal vez las tres visiones puedan ser comentarios, en el sentido foucaultiano del término, ya que de esta manera el azar contenido en el discurso (en este

7 Se prefiere usar el término "americanista" y no "nacionalistas" ni "peruanos" ni "bolivianos", ya que era el término que el movimiento patriota se adjudicaba a sí mismo, sobre todo durante las guerras de Independencia en Sudamérica entre 1810 y 1824. 
caso la partitura) puede ser contenido o conjurado mediante el continuo desarrollo de discursos y metadiscursos.

De acuerdo con estas tres perspectivas, es posible conectar las ventajas y desventajas de una visión complementaria de todas ellas, como muestra el siguiente esquema (ver Figura $\left.\mathrm{N}^{\circ} 1\right)$ :

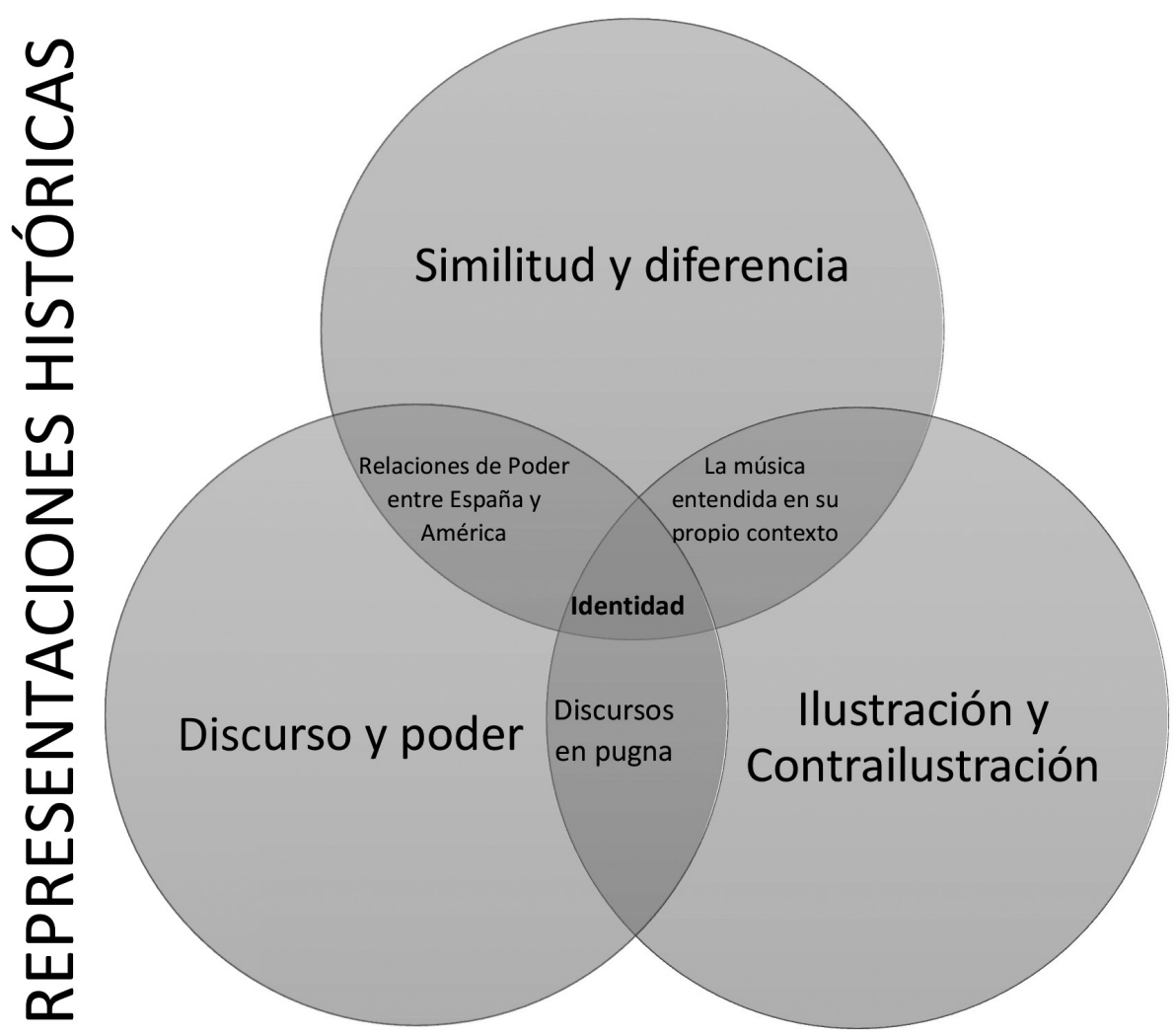

Figura $\mathrm{N}^{0}$ 1. Complementariedad de las narrativas propuestas (Elaboración propia).

No necesariamente las representaciones históricas deben guardar entre sí puntos en común. En muchas ocasiones no los tienen y sus construcciones son absolutamente divergentes. En el caso de las tres visiones que motivan este trabajo, podríamos señalar algunas coincidencias explícitas (como la música entendida en su propio contexto que tanto Miranda como Izquierdo coinciden en resaltar), otras implícitas y no expresadas (como los discursos en pugna, tanto en la visión de Ilustración y Contrailustración como en la de Discurso y Poder) y otras inferidas (las relaciones de poder entre España y América, vistas desde perspectivas diferentes).

Si tuviera que ser necesaria una metarrepresentación integrando elementos de las otras tres, las formas de expresarlas serían infinitas, dependiendo del investigador. Por ejemplo, 
podría decirse que las pugnas en torno al poder expresadas por medio de recursos sonoros podrían haber elegido los caminos de la similitud y la diferencia, o de la Ilustración y la Contrailustración.

Revisando más de cerca la propuesta bipartita de Miranda, quizás tendría lugar una tercera posibilidad, la que es posible inferir de sus postulados: el intento de escribir obras que incluyesen elementos de ambos mundos y que usaran lenguajes y estructuras europeas con materiales melódicos y rítmicos procedentes de otras culturas sonoras. Esta simbiosis obedecería a un intento ilustrado de universalización. En Ximénez, aunque los materiales procedentes de la tradición oral o de la música de salón no se encuentran en la totalidad de su obra, su presencia en parte de la misma podría deberse a un discurso americanista, que intenta construir una identidad propia con un lenguaje erudito que tendría como objetivo poner su trabajo (y por esta razón a quienes lo escuchan) al mismo nivel que sus pares europeos, dando de esa manera legitimidad no solo a su práctica compositiva e interpretativa musicalmente hablando, sino a todo el proyecto independiente que en esa época se encontraba en el apogeo de su gestación y difusión. En este caso, el lenguaje de Ximénez obedecería a un deseo de emulación de la música europea, un afán de integrarse a ella, aunque incorporando citas localistas para marcar claramente su procedencia, como lo ha señalado Izquierdo.

De esta manera podría argumentarse que la inclusión de música tradicional en obras formalmente pertenecientes al clasicismo se debería a la necesidad de construir una identidad sonora dentro de un proyecto artístico emparentado con la construcción de naciones y Estados, que buscó primero legitimar discursos políticos independientes de la metrópoli, y una vez alcanzado su objetivo, se dedicó a la construcción de identidades sonoras diferenciables, pero técnicamente equiparables con las europeas.

\section{A MANERA DE CONCLUSIÓN}

Después de recorrer estas tres interpretaciones, regresamos a Ankersmit, cuando dice que "una manera interpretativa de ver el pasado solo puede reconocerse como tal en presencia de otras formas de ver el pasado. Las interpretaciones narrativas se definen mutuamente entre sí y por tanto debe su identidad a sus relaciones intertextuales" (Ankersmit 2014: 145) y que "la idea histórica no tiene un carácter cognitivo, sino que es en esencia una propuesta de cómo debe verse el pasado. No es conocimiento, sino una organización del conocimiento" (Ankersmit 2014: 189). Las propuestas mencionadas en este trabajo no son definitivas, últimas ni mutuamente excluyentes. Suponen, como diría Hayden White, un "acto poético", una prefiguración del campo histórico para poder explicarlo desde su propia narrativa (White 1992: 39). O tal vez las tres visiones puedan ser comentarios, en el sentido foucaultiano del término ${ }^{8}$, ya que de esta manera el azar contenido en el discurso (en este caso la partitura) puede ser contenido o conjurado. La mayor cantidad de interpretaciones pueden ayudarnos a construir una historiografía si no exacta, porque el pasado sigue siendo inaprensible, por lo menos más aproximada a lo que pudo ser ese pasado.

8 "El comentario conjura el azar del discurso al tenerlo en cuenta, permite decir otra cosa aparte del texto mismo, pero con la condición de que sea ese mismo texto el que se diga, y en cierta forma, el que se realice" (Foucault 1992: 24). 


\section{BIBLIOGRAFÍA}

Alzedo, José Bernardo

2018 [1868]. Filosofía Elemental de la Música. La exégesis de las doctrinas conduscentes a su mejor inteligencia. Lima: Universidad Nacional de Música.

Ankersmit, Franklin

2014 Historia y Tropología. Ascenso y caída de la metáfora. México: Fondo de Cultura Económica.

BERLIN, ISAIAH

2006 Contra la corriente. Ensayos sobre Historia de las ideas. México: Fondo de Cultura Económica.

Burke, Peter

$2000 \quad$ Formas de Historia Cultural. Madrid: Alianza Editorial.

Contreras Cortés, Francisco

1984 “Clasificación y tipología en arqueología. El camino hacia la cuantificación”, Cuadernos de prehistoria y arqueología de la Unviersidad de Granada 9, pp. 327-385.

Foucault, Michel

1992 El orden del discurso. Buenos Aires: Tusquets.

Ginzburg, Carlo

1999 El queso y los gusanos. El cosmos, según un molinero del siglo XVI. Barcelona: J\&B.

IzQuierdo KöNIG, José MANUEL

2016a "El militar retirado de Pedro Jiménez de Abrill (Arequipa 1784-Sucre, 1856): Una tonadilla inédita en el Perú independiente”, Diagonal, an iberoamerican music review, 1/2. DOI: https:/ / doi.org/10.5070/D81231993

2016b Ilustración y contra ilustración de un cuarteto arequipeño (o cómo escribir un yaraví en el estilo de Haydn). Lucca: Librería Musicale Italiana.

2016c "Las Sinfonías de Pedro Ximénez Abrill y Tirado: una primera aproximación”, en Anuario de Estudios Bolivianos Archivísticos y Bibliográficos, 22/1, pp. 153-184.

2017 "Being a Composer in the Andes during the Age of Revolutions. Choices and Appropriations in the Music of José Bernardo Alzedo and Pedro Ximénez Abrill Tirado”. Tesis doctoral. Cambridge University. DOI: https://doi.org/10.17863/CAM.12398 [acceso: 13 de enero, 2018].

IzQuierdo König, José Manuel, y Zoila Vega Salvatierra

2017 "Nuevos aportes acerca de la vida del compositor peruano-boliviano Pedro Ximénez Abrill Tirado (1784-1856)", Revista Musical Chilena, LXXI/227 (enero-junio), pp. 48-78. DOI: http:/ /dx.doi.org/10.4067/s0716-27902017000100048

Miranda, Ricardo

2011 "La música en Latinoamérica en el siglo XIX", La música en Latinoamérica, Ricardo Miranda y Aurelio Tello (autores), Mercedes de Vega (coordinadora). Colección La Búsqueda perpetua: Lo propio y lo universal de la cultura latinoamericana, vol. 4. México: Ediciones de la Secretaría de Relaciones Exteriores, pp. 21-137. Disponible en https://acervo.sre.gob.mx/images/ libros/cultura/4_musica.pdf [acceso: 14 de mayo, 2017].

Sicramio (SEUD.)

1791 "Rasgo emitido a la sociedad sobre la música en general y particularmente de los yaravíes", Mercurio Peruano, III/101, pp. 284-291. Disponible en http://www.cervantesvirtual.com/ obra/mercurio-peruano-13/ [acceso: 25 de septiembre, 2018].

Turino, Thomas

2003 "Nationalism and Latin American Music: Selected Case Studies and Theoretical Considerations”, Latin American Music Review / Revista de Música Latinoamericana, XXIV/2 
(otoño-invierno, 2003) pp. 169-209. Disponible en https://www.jstor.org/stable/3598738 [acceso: 20 de mayo, 2017].

VARGAS, EDUARDO

2012 Pedro Ximenez Abrill"s Symphony No. 11: Editorial Research and Performance Considerations for Modern Premiere. University of North Carolina, Grensboro, disponible en https://libres. uncg.edu/ir/uncg/f/Vargas_uncg_0154D_10975.pdf [acceso: 23 de noviembre, 2020].

Vega Salvatierra, Zoila

2018 "La partitura como testimonio de la tradición. Un caso sobre identidad y etnomusicología en la historia”, Cuadernos de Música Iberoamericana, 31 (enero-diciembre), pp. 211-233. DOI: https://doi.org/10.5209/CMIB.62293

White, Hayden

2010 Metahistoria. México: Fondo de Cultura Económica. 